\title{
Acoustic performances of silicone foams for sound absorption
}

\author{
Ahmed Abbad, Kévin Jaboviste, Morvan Ouisse, Nicolas Dauchez ${ }^{\dagger}$ \\ Draft version accepted for publication in Journal of Cellular \\ Plastics, 2017
}

\begin{abstract}
The aim of this study is the investigation of the link between the elaboration process, the microstructure and the acoustic behaviour of silicone foams obtained using a two-component silicone. Different parameters are varied such as the ratio of components, the addition of a thinning agent and the curing temperature, with the objective of understanding the influence of each parameter in the foam's acoustic absorption. The microstructure is analysed using SEM and acoustic properties are measured. Two non-acoustical properties of the porous material are also investigated, namely the porosity and the flow resistivity. Pore cell size and inter-connected porosity have great impact on acoustical properties. Significant enhancements of the absorption properties could be obtained in the low frequency band by increasing the rate of agent B through an increase in the amount of interconnected porous cells. An improvement in absorption is observed in the higher frequency range when a thinning agent is added to the mixture. Representative models of the foam for acoustic simulations are obtained allowing estimation of the tortuosity, viscous and thermal characteristic length from acoustic measurements. These models are able to simulate the acoustic behaviour of the silicone foams when embedded in sound packages.
\end{abstract}

\section{Introduction}

Noise pollution and its effects on human wellbeing, wildlife and economy is a growing concern $[1,2]$. Many researches are currently focused on the reduction of vibrations and noise, in order to improve comfort in transports, environment and buildings constructions [3, 4]. Among others, the use of porous materials is a solution allowing vibroacoustic control with low weight addition [5], even

\footnotetext{
*Univ. Bourgogne Franche-Comté, FEMTO-ST Institute, CNRS/UFC/ENSMM/UTBM, FR

†Sorbonne universités, Université de Technologie de Compiègne, Laboratoire Roberval, FR
} 
if recyclability remains a challenging issue $[6,7]$. Moreover, lightness is often associated to low mechanical properties [8], in particular in terms of failure [9]. This could imply short lifetimes, in particular when the mechanical sollicitations are combined with thermal degradations [10]. This last point motivates the study of materials with high mechanical properties in terms of failure, as alternative to open cells polyurethane (PU) foams, natural or mineral fibrous materials which are currently the most used materials for vibroacoustic control.

These acoustic materials are generally designed to absorb sound energy. Their performances are generally characterized with the sound absorption coefficient (often noted $\alpha$ ). This coefficient varies from 0 (total reflection) to 1 (total absorption) $[5,11]$. It should be noted that these materials exhibit poor acoustic performances at low frequencies [12]. The frequency evolution of the sound absorption coefficient is strongly dependent of the microstructure [13]. Large differences in acoustic behavior are then observed between materials, because of the various microstructure geometries. Among others, the importance of the structure and pore size distribution for the acoustic performances and vibration damping has been pointed in many studies, for various materials. In particular, PU foams are widely used since they constitue a good compromise between vibroacoustic behavior, cost and manufacturability [14]. Other properties like thermal insulation [15], flame behavior [16] or biodegradability [17] are described in the literature. Despite the advantages exhibited by polyurethane foams (low price and lightness), this material has several disadvantages, among which the fact that polyurethane is polluting in its composition and its production. In this paper, we focus on the use of an alternative foam for acoustic applications, namely a silicone foam which is highly resilient and exhibits interesting mechanical properties [18].

Understanding the link between elaboration parameters, foam cells morphology and acoustic performances is a key point for the design of efficient solutions. For instance, Zhan et.al [14] investigated the influence of the cell morphology (pore size, open porosity) on the sound absorption performance of PU materials. Micro-macro approaches would allow to understand the link between production process and acoustic absorption performances $[19,20]$. These approaches allow for estimation of acoustical performances of any arbitrary material but require advanced computational considerations. When the analysis is restricted to a family of well-known materials, semi-empirical approaches may be used [21, 22]. All these techniques are generally used to estimate some meso-scale parameters, among which porosity, tortuosity, flow resistivity, viscous and thermal characteristic lengths [5]. Each of these parameters is related to the microstructure, but they can be seen as intrinsic parameters of equivalent homogeneous materials. A lot of models have been developed to describe the acoustic behavior of porous media [5] from the knowledge of the meso-scale parameters. Some models also take into account the motion of the skeleton, they are generally based on the Biot approach [23]. For existing foams, the micro scale parameters are generally estimated from optical measurements [14, 21], while the meso scale parameters may be estimatied from experimental measurements, either from dedicated setups [24] or global acoustic measurements following inverse 
procedures [25].

Acoustic properties of silicone foams have been little discussed in the literature. One may mention the work of Lee [26] or Kumar [27], that focus on single part liquid silicone rubber. Moreover, to the authors' knowledge, no paper provides the required input parameters for using acoustic porous models allowing estimation of acoustic performances when these materials are used in single layers or included in complex sound packages that can be described with the Transfer Matrix Method [5].

The objective of this paper is to investigate how the elaboration parameters affect the microstructure (pore cell size, open porosity) and the absorption performance of silicone foams. First, some elaboration parameters (components ratio, curing agent, curing temperature) are varied and different samples are synthesized. Parameters are identified at micro and meso levels in order to establish their link with elaboration parameters. Finally, acoustic absorption coefficients are measured for the various samples, and compared to the ones obtained with Delany-Bazeley [28] and Johnson-Champoux-Allard [29] models.

\section{Materials and methods}

\section{$2.1 \quad$ Material}

This material used in this work is the silicone foam named Bluesil RT Foam 3240 (Bluestar Silicones, France). This material is supposed to be used in different applications, among which production of printing rollers, orthopaedic pieces or insulation of noise and heat.

The elaboration process of this foam has interesting features, such as easy curing, or an extra soft hardness of 40 in Shore 00 scale. Moreover the material expands without employing ozone depleting CFCs or other related blowing agents.

The material of interest is a two-components silicone foam which cures at room temperature by a cure reaction (Eq.1). The bimodal foam is obtained by mixing two liquid components, namely the polymer (referred as A in the following) and the curing agent (B), which will expand and cure to the foam elastomer:

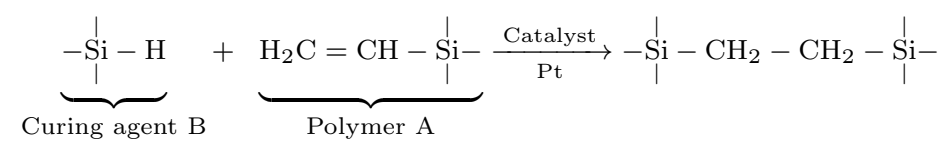

\subsection{Experimental protocol}

The samples are formed using cylindrical moulds with diameters $29 \mathrm{~mm}, 44.5$ $\mathrm{mm}$ and $100 \mathrm{~mm}$. The samples are aged at room temperature during 24 hours, before being cut using water jet in order to obtain plane surfaces on the top surfaces of the samples. All samples have a common thickness of $20 \mathrm{~mm}$. Typical samples are shown in Fig.1. 


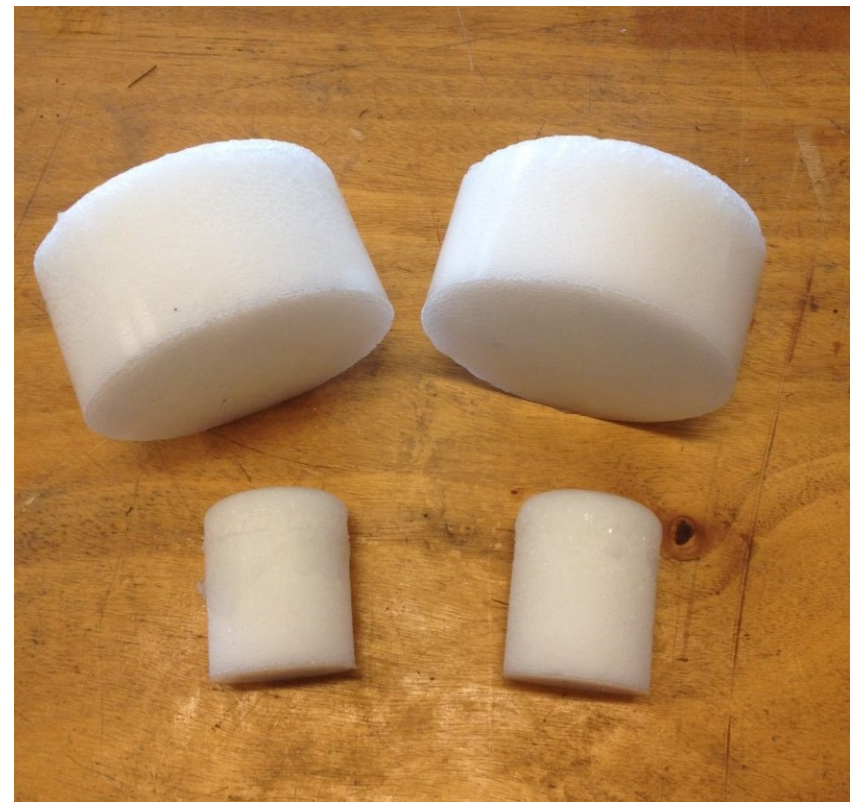

Figure 1: Silicone foam samples after foaming and demolding

Different parameters are varied during the elaboration process in order to investigate their impact on the microstructure and the acoustic behavior:

- A/B ratio (volume ratio between polymer and curing agent);

- addition of a thinning agent (a polydimethylsiloxane oil);

- curing temperature.

These parameters are described in the following subsections. As it will be shown later, these 3 parameters impact both the cell morphology and the acoustic performances of the foam.

\subsubsection{A/B ratio}

According to the technical datasheet, it is recommended to use a ratio $\mathrm{A} / \mathrm{B}=1$. The respective amount of the components $\mathrm{A}$ and $\mathrm{B}$ are varied to prepare samples having different properties compared to the reference (50\% A and 50\% B). Tab. 1 lists the elaborated samples.

\subsubsection{Thinning agent}

The thinning agent Bluesil oil $47 \mathrm{~V}$ is a polydimethylsiloxane oil. It is constituted of linear molecular chains of varying lengths whose groups comprise 


\begin{tabular}{|c|c|c|}
\hline sample & $\% \mathrm{~A}$ & $\% \mathrm{~B}$ \\
\hline ref & 50 & 50 \\
\hline $30 \mathrm{~A}$ & 30 & 70 \\
\hline $70 \mathrm{~A}$ & 70 & 30 \\
\hline
\end{tabular}

Table 1: Description of the configurations ref, 30A and 70A

altering silicon and oxygen atoms (the Si-O-Si siloxane bond). This oil is used as thinning agent for RTV and silicone sealants, and anti-blotting products for photocopying machines. In our study, amounts of $5 \%$ or $25 \%$ of oil in the foam are used, based on the reference sample (initially composed by $50 \% \mathrm{~A}$ and $50 \%$ $\mathrm{B})$.

\begin{tabular}{|c|c|c|c|}
\hline sample & $\% \mathrm{~A}$ & $\% \mathrm{~B}$ & Oil (\% in $\mathrm{A}+\mathrm{B})$ \\
\hline $5 \mathrm{H}$ & 50 & 50 & 5 \\
\hline $25 \mathrm{H}$ & 50 & 50 & 25 \\
\hline
\end{tabular}

Table 2: Oil variation for the samples $5 \mathrm{H}$ and $25 \mathrm{H}$

\subsubsection{Curing temperature}

The silicone foam 3240 polymerizes at room temperature $\left(22^{\circ} \mathrm{C}-25^{\circ} \mathrm{C}\right)$. However, the variation of temperature was investigated to understand its influence on the microstructure and the acoustical behavior (Table 3).

\begin{tabular}{|c|c|c|c|}
\hline sample & $\% \mathrm{~A}$ & $\% \mathrm{~B}$ & Temperature $\left[{ }^{\circ} \mathrm{C}\right]$ \\
\hline ref & 50 & 50 & 25 \\
\hline $40 \mathrm{~T}$ & 50 & 50 & 40 \\
\hline
\end{tabular}

Table 3: Curing temperature for sample 40T

\subsection{Measurement methods}

Understanding the link between the microstructure of a material and its macroscopic properties is of great interest to predict its functional properties, allowing optimization of the material for practical applications. In the following, the measurement methods used in this work are described. 


\subsubsection{Microgeometry analysis}

The average diameter and distribution of pores are determined with Scanning Electron Microscopy (SEM). Samples are mounted on metal sample stubs with adhesive tapes, and sputter-coated with carbon or/and gold. The image analysis is performed with ImageJ software [30].

\subsubsection{Non acoustic properties}

Two non-acoustic properties are investigated: static flow resistivity and open porosity. The air flow resistivity is an important meso-scale physical characteristic of sound absorbing porous materials. It describes the viscous interaction between the air and the material [5]. The static flow resistivity $\sigma$ of our samples was studied using the static airflow resistivity meter. The system is based on the direct method described in the ASTM C 522 which consists in imposing of flow rate $\mathrm{Q}$ in the sample and measuring the resulting pressure difference $\Delta P$ as illustrated in figure 2. The open porosity $\Phi$ is defined as the fraction

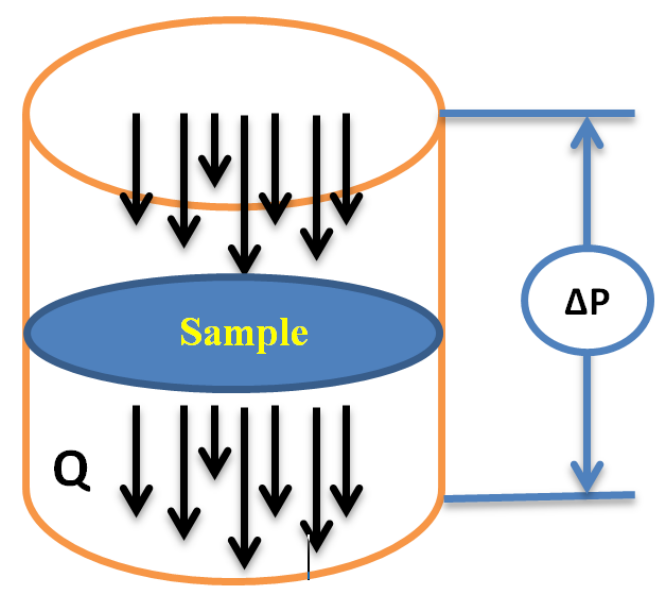

Figure 2: Air flow resistivity measurement principle

of volume that is occupied by the fluid in the interconnected porous network. Non-interconnected voids trapped in the solid phase are not part of the open porosity (closed porosity). The bulk density $\rho$ is the vacuum density of the porous aggregate. The porosity meter is based on the pressure/mass isothermal method which allows measuring the mass of the test sample filled by gas at different pressures. From the perfect gas law, the volume of the solid phase is obtained from which the bulk density and open porosity of the material are deduced. Argon gas is used (the accuracy of the method increases with the bulk 
volume of sample and the density of the gas). Measurements are conducted at Roberval laboratory, UTC, FR, on Mecanum apparatus.

\subsubsection{Absorption coefficient and surface impedance}

The sound absorption coefficient and the surface impedance were obtained by using a two-microphone impedance tube from Brüel \& Kjær. The tests were performed according to the standard procedure detailed in ASTM E1050-10. The absorption coefficient was measured using cylindrical foam samples, $29 \mathrm{~mm}$ diameter and $20 \mathrm{~mm}$ thick, over the frequency range of $10-5000 \mathrm{~Hz}$. The incident sound wave was normal to the surface of the foam rise direction. Each of the tests was repeated three times to obtain consistent and representative results. While microstructural and non-acoustic properties do not depend on the size of the sample, absorption coefficient and surface impedance do: they mainly depend on the sample thickness [5]. In this work, all samples have the same thickness. For applications involving this material with other thickness, the microstructural and non-acoustic parameters will remain the same, while acoustic properties will change. However, with the models proposed later in this paper, the acoustic coefficient and surface impedance can be computed for any sample thickness, using the non-acoustic parameters provided here.

\section{Results and discussion}

\subsection{Cell/pore morphologies and size distribution}

Fig. 3 shows a SEM image of the reference sample. It can be observed that most of the pores are open, with circular interconnection between adjacent pores. The number, size and type of pores are key factors for the sound absorption mechanisms in these materials, since they are related to viscous losses when acoustic wave propagate in the foam [5].

The figure 6 shows SEM images of samples $30 \mathrm{~A}$ and $70 \mathrm{~A}$. It is clear that changing the A/B ratio has an effect on the morphology. This effect may be quantified by statistical analysis of the SEM images.

Figures 7 and 8 show the statistics of pore and interconnection size for reference and $30 \mathrm{~A}$ samples.

Statistics of the full set of samples are illustrated through their box plots which are given in figures 9,10 , while mean and standard variations are provided in table 4.

Regarding interconnection size, the average for the reference (ref) sample containing $50 \%$ of $\mathrm{A}$ and $50 \%$ of B is $0.13 \mathrm{~mm}$. When the curing oil is added, this average increases. $5 \mathrm{H}$ sample has the largest interconnection diameter $(0.22$ $\mathrm{mm}$ ). The gap between samples $5 \mathrm{H}$ and $25 \mathrm{H}$ is about $13 \%$ and increases to $71 \%$ when compared to the reference sample. The addition of the oil contributes to the increase in size of the cells. No significant effect is observed for the other components. Increasing the ratio of the B component has almost no effect, and 


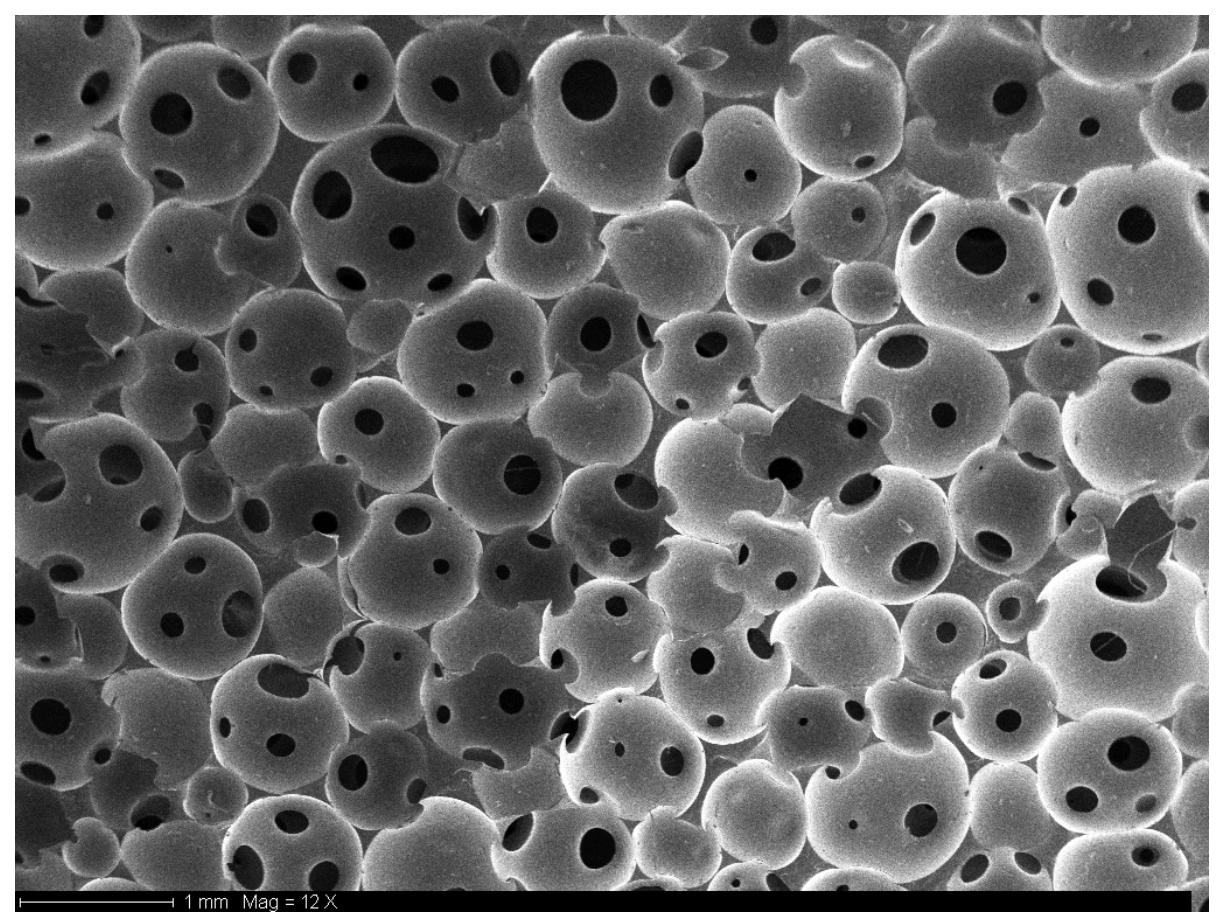

Figure 3: SEM image of the reference sample

\begin{tabular}{|c|c|c|c|c|c|c|}
\hline Sample & ref & $5 \mathrm{H}$ & $25 \mathrm{H}$ & $30 \mathrm{~A}$ & $70 \mathrm{~A}$ & $40 \mathrm{~T}$ \\
\hline $\begin{array}{c}\text { Average } \\
\text { inter- } \\
\text { con. } \\
{[\mathrm{mm}]}\end{array}$ & 0.13 & 0.22 & 0.19 & 0.13 & 0.16 & 0.12 \\
\hline $\begin{array}{c}\text { Std.dev. } \\
\text { inter- } \\
\text { con. } \\
{[\mathrm{mm}]}\end{array}$ & 0.019 & 0.008 & 0.001 & 0.012 & 0.025 & 0.003 \\
\hline $\begin{array}{c}\text { Average } \\
\text { cell diam. } \\
\text { [mm] }\end{array}$ & 0.77 & 0.83 & 1 & 0.74 & 0.85 & 0.68 \\
\hline $\begin{array}{c}\text { Std.dev. } \\
\text { cell } \\
\text { diam. }[\mathrm{mm}]\end{array}$ & 0.05 & 0.045 & 0.024 & 0.025 & 0.03 & 0.06 \\
\hline
\end{tabular}

Table 4: Cell diameter and interconnection statistics 


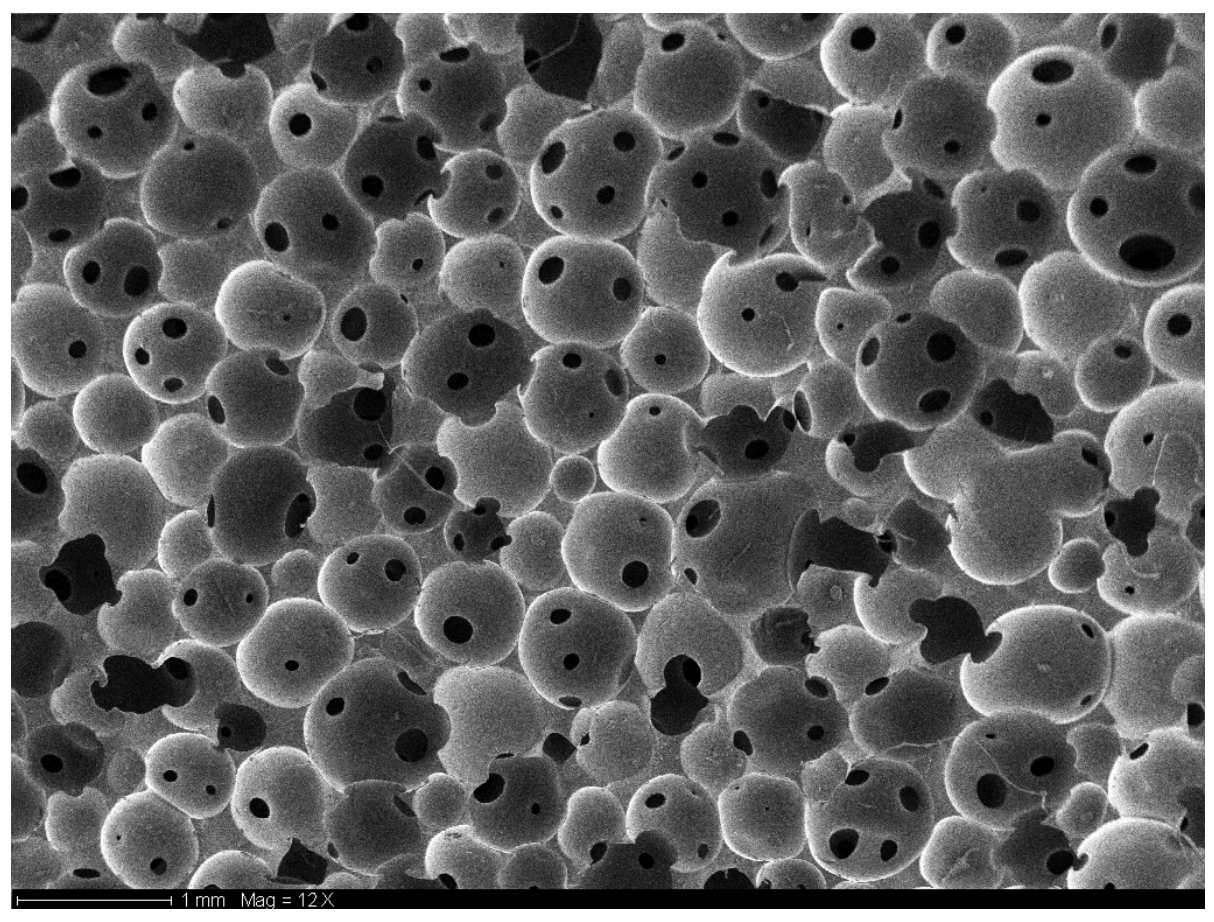

Figure 4: *

a) $30 \mathrm{~A}$ sample 


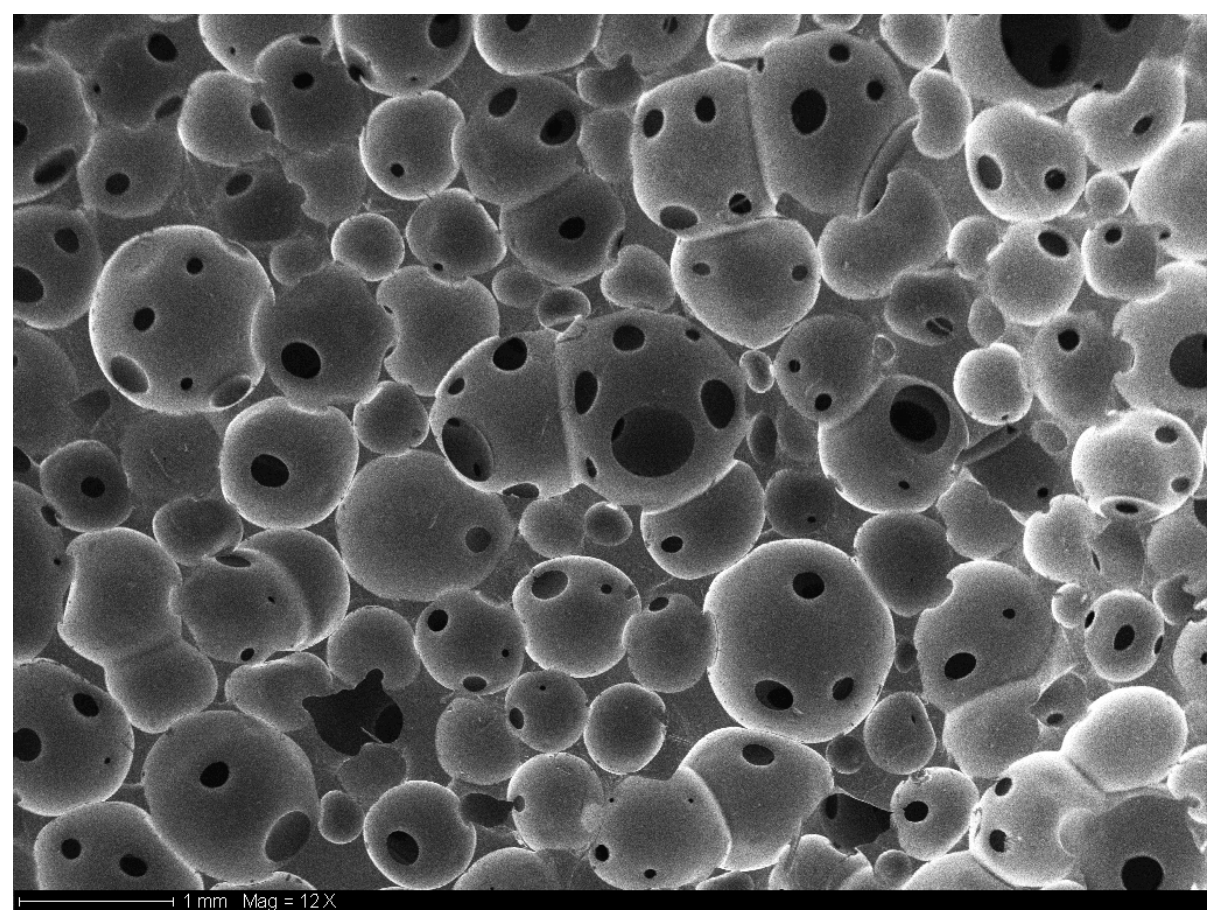

Figure 5: *

b) $70 \mathrm{~A}$ sample

Figure 6: SEM images of samples $30 A$ and $70 A$ curing at room temperature 

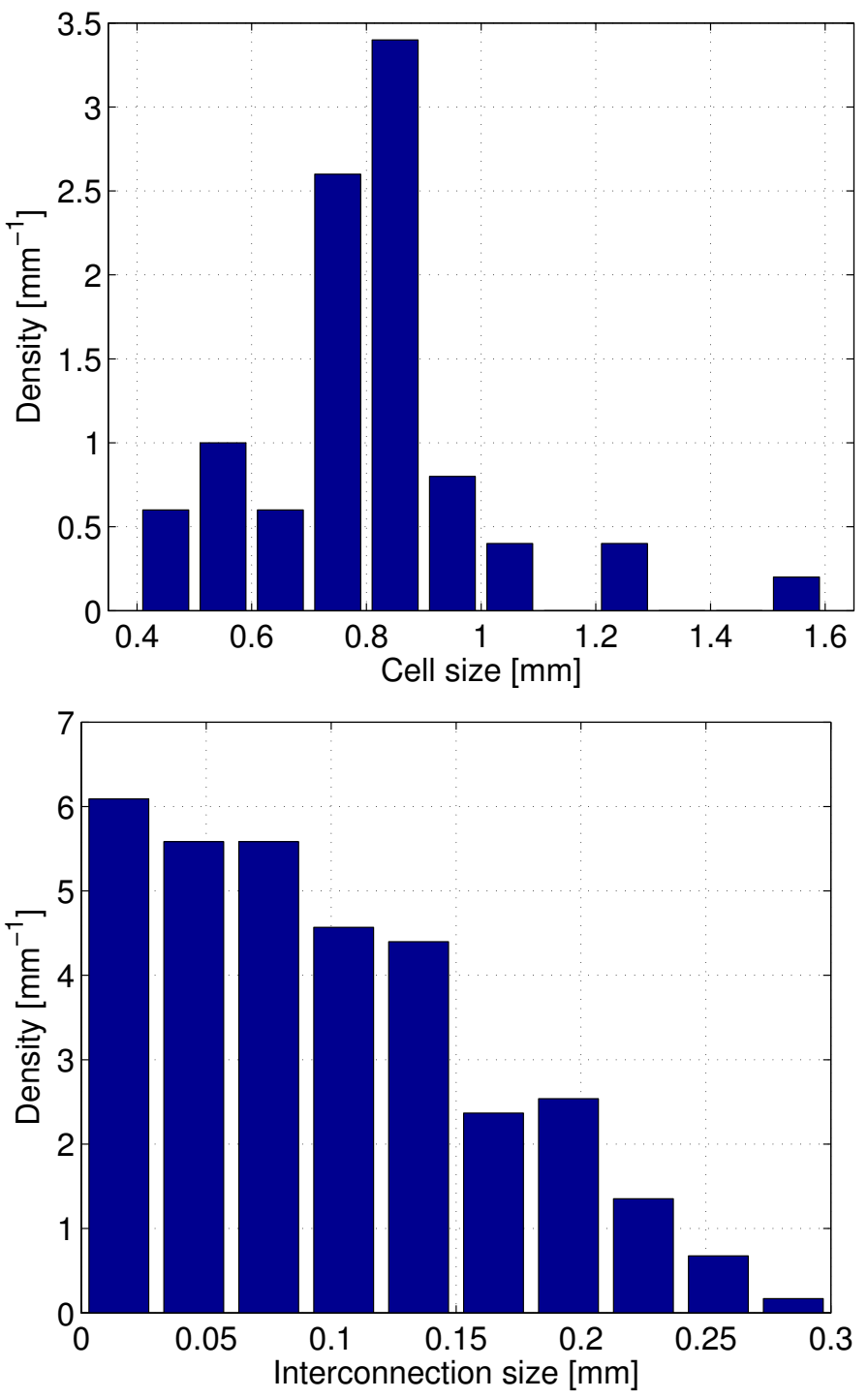

Figure 7: Cell and interconnection sizes distribution for ref sample 

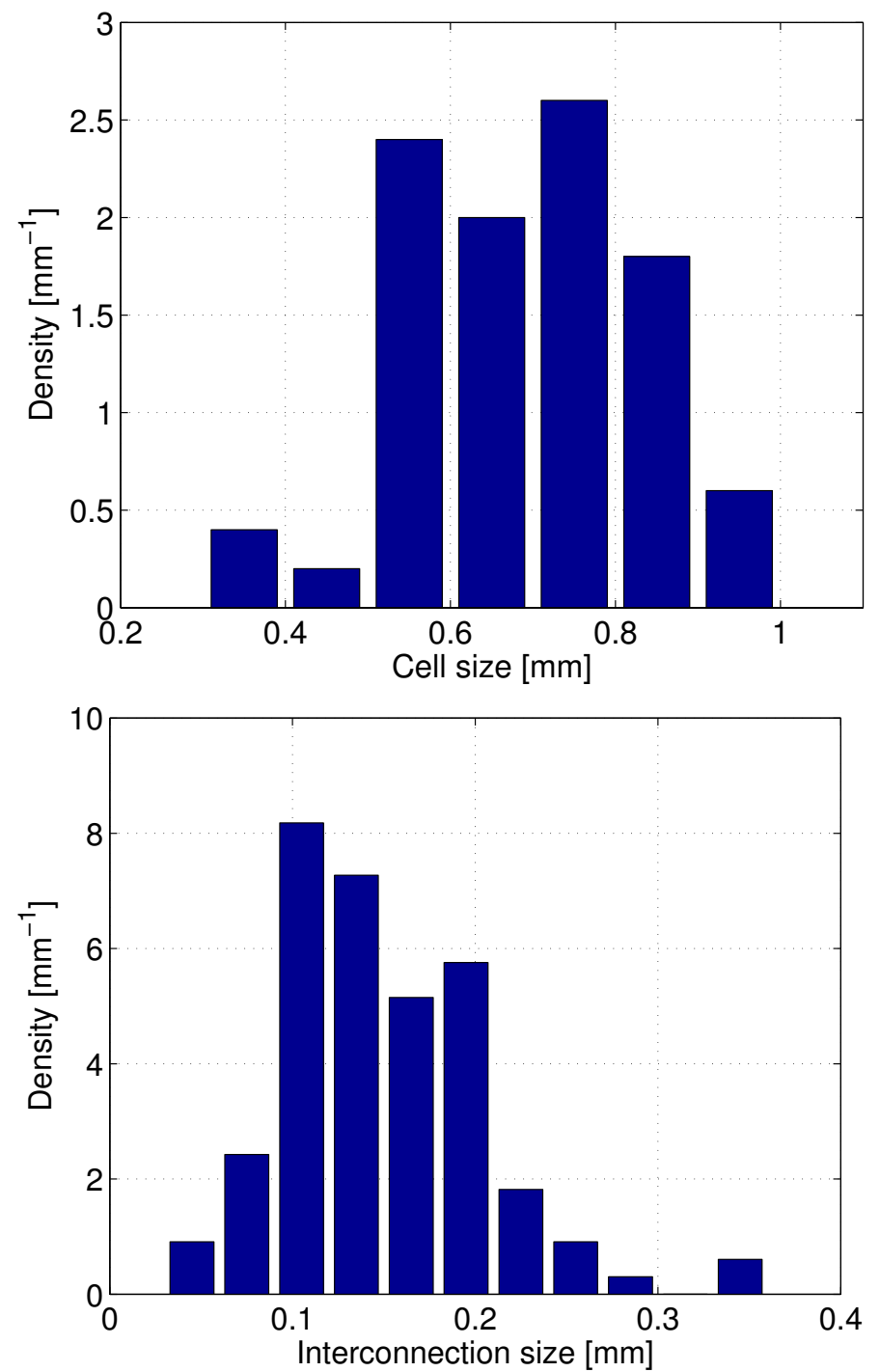

Figure 8: Cells and interconnection pores sizes distribution for 30A sample 
increasing the A component has little impact on the morphology of the pores. Also, the curing temperature has no significant contribution.

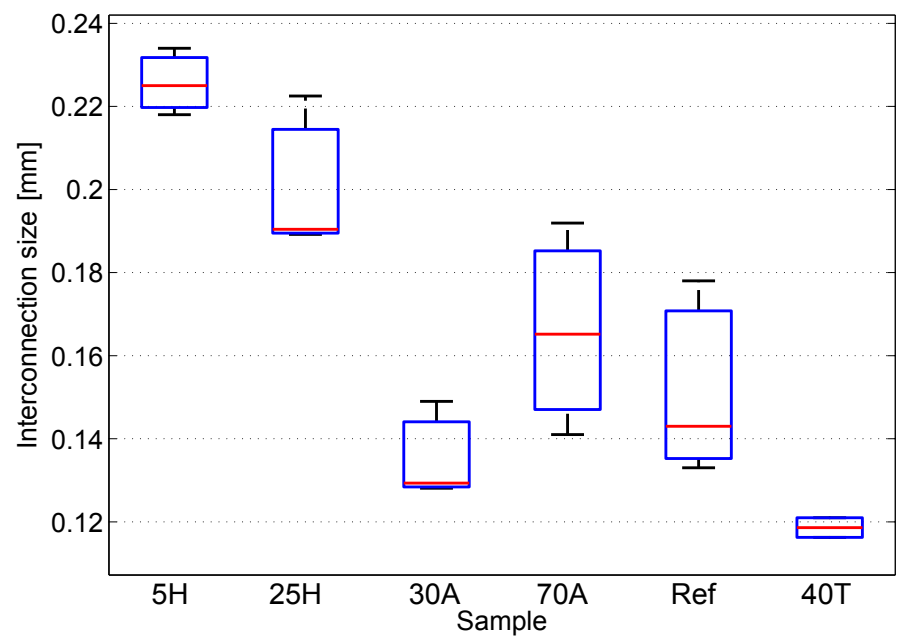

Figure 9: Box plot of the interconnection size distribution for the samples of interest

The largest cell diameter of $1 \mathrm{~mm}$ is observed for $25 \mathrm{H}$ sample. Adding curing oil increases the pore size. The oil slows the curing process, allowing higher swelling of the cells before reticulation. The same trend is observed when the part B (curing agent) is lower than the part A (70A): the mean cell diameter is $0.85 \mathrm{~mm}$ and the $\mathrm{A} / \mathrm{B}$ ratio influences rather the number and nature of the pores. The high curing temperature (40T) tends to decrease the pores size. When the temperature is increased, the curing process is faster, limiting the swelling, which explains the smaller cell size. In comparison, the reference pore cell size curing at room temperature is $11 \%$ higher than for $40 \mathrm{~T}$. The ratio of each type of cell is investigated and represented in Tab. 4.

\begin{tabular}{|c|c|c|c|c|}
\hline Sample & ref & $30 \mathrm{~A}$ & $70 \mathrm{~A}$ & $25 \mathrm{H}$ \\
\hline Partially open (\%) & 84 & 51 & 75 & 77 \\
\hline Totally open (\%) & 10 & 22 & 10 & 14 \\
\hline Closed (\%) & 6 & 27 & 14 & 9 \\
\hline
\end{tabular}

Table 5: Average of Cell/Interconnection porosity

A specificity of this material, which is usually not observed on classical PU foams, is the relatively large amount of partially open cells. The figure 11 illustrates the distinction between closed, totally open and partially open cells. Most of the time, the distinction is clear between the three types of pores. 


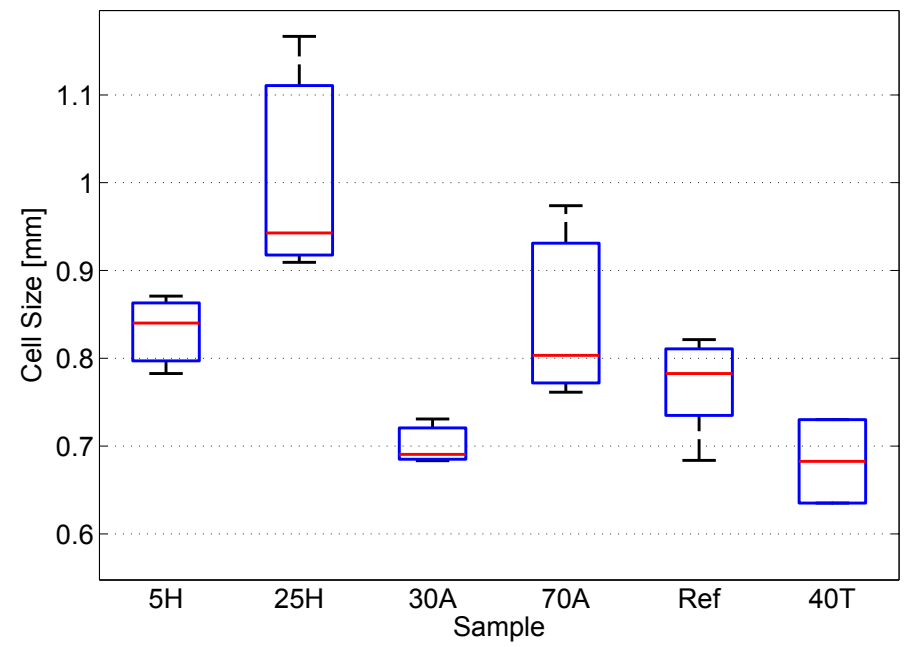

Figure 10: Box plot of the cell size distribution for the samples of interest

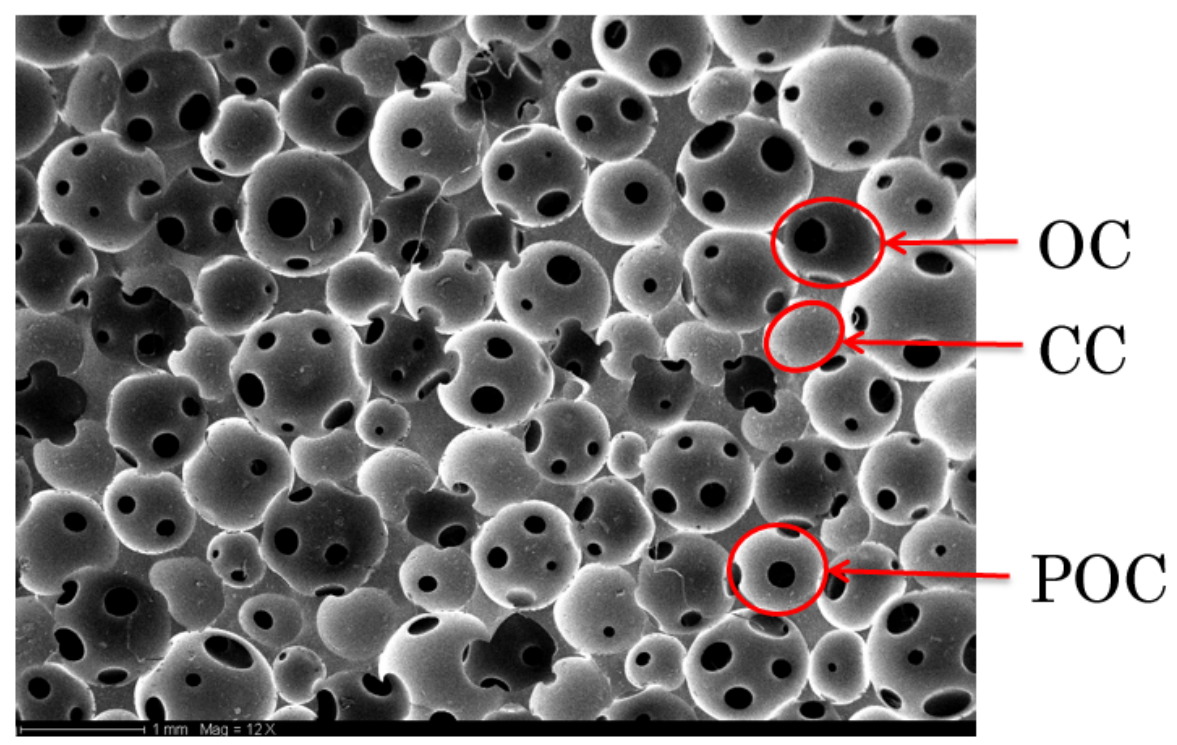

Figure 11: Illustration of Open Cells (OC), Closed Cells (CC) and Partially Open Cells (POC) 
We hence notice, for all samples, a large ratio of partially open cells, a small amount of completely open cell and a low ratio of closed cell (Fig.6). The reference sample (Fig. 6(a)) contains $84 \%$ of partially open cells, which is the largest ratio of the tested samples. Sample 30A (Fig. 6(b)) has the lowest amount of partially open cells, and the largest ratio of open cells and closed cells. Compared to the reference, $25 \mathrm{H}$ (Tab. 5) has more totally open and closed cells. The $70 \mathrm{~A}$ and $25 \mathrm{H}$ samples have almost the same ratio of partially open cells.

The changes in the microstructure also impact the density of the foam. Table 6 provides the values of the average densities of the samples. The datasheet of the reference material indicates a value of $200 \mathrm{~kg} \cdot \mathrm{m}^{-3}$. As it can be seen from the table 6 , deviations from the reference configuration (ie. $\mathrm{A} / \mathrm{B}=1$ ) result in an increase of the density of the foam. This is mainly due to the slower foaming process that increases the amount of closed cells.

\begin{tabular}{|c|c|c|c|c|}
\hline Sample & ref & $30 \mathrm{~A}$ & $70 \mathrm{~A}$ & $25 \mathrm{H}$ \\
\hline Average [kg.m $^{-3}$ ] & 189 & 239 & 255 & 247 \\
\hline NSD (\%) & 5.7 & 6.8 & 3.3 & 0.5 \\
\hline
\end{tabular}

Table 6: Density of samples: mean values and Normalized Standard Deviations (NSD, ratio between mean and standard deviation)

\subsection{Elaboration process influence on the meso scale prop- erties}

The table 7 shows the values of the two meso scale parameters of interest, namely air flow resistivity and porosity, for four $100 \mathrm{~mm}$ diameter samples. The values

\begin{tabular}{|c|c|c|}
\hline Sample & $\sigma\left[\right.$ N.s.m $\left.^{-4}\right]$ & $\Phi$ \\
\hline ref & 11010 & 0.80 \\
\hline $70 \mathrm{~A}$ & 23085 & 0.93 \\
\hline $30 \mathrm{~A}$ & 81902 & 0.91 \\
\hline $25 \mathrm{H}$ & 11258 & 0.86 \\
\hline
\end{tabular}

Table 7: Resistivity and porosity of silicone foam samples

obtained for the ref and $25 \mathrm{H}$ foams are typical of low air resistivity polymeric foams. The values for $70 \mathrm{~A}$ are twice and are even higher for the $30 \mathrm{~A}$ which corresponds to a highly resistive material. This sample has the largest pore size and the smallest size of interconnections between the pores. This explains that the $30 \mathrm{~A}$ is the more absorbing material in the low frequency range.

Porosities values given in table 6 are quite large (over 0.8). They correspond to the typical sound absorbing materials and confirm the ability of the silicone foams to absorb sound efficiently. 


\subsection{Acoustic behavior}

\subsubsection{Process repeatability}

The goal of this section is to check if the elaboration process is repeatable regarding acoustic properties. Figure 12 shows the absorption coefficient of four supposed identical samples ref (29 $\mathrm{mm}$ diameter, $20 \mathrm{~mm}$ thick) made separately with the same proportion of Part A and B and cured at room temperature. The four curves, shown in the same figure, are very close one to another, which illustrate the good repeatability of the elaboration process. Under $3 \mathrm{kHz}$, all samples exhibit the same behaviour. Above that value, one of the samples has a slightly different behaviour from the others (ref01), the difference being however limited to a maximum of $8 \%$ at $5 \mathrm{kHz}$.

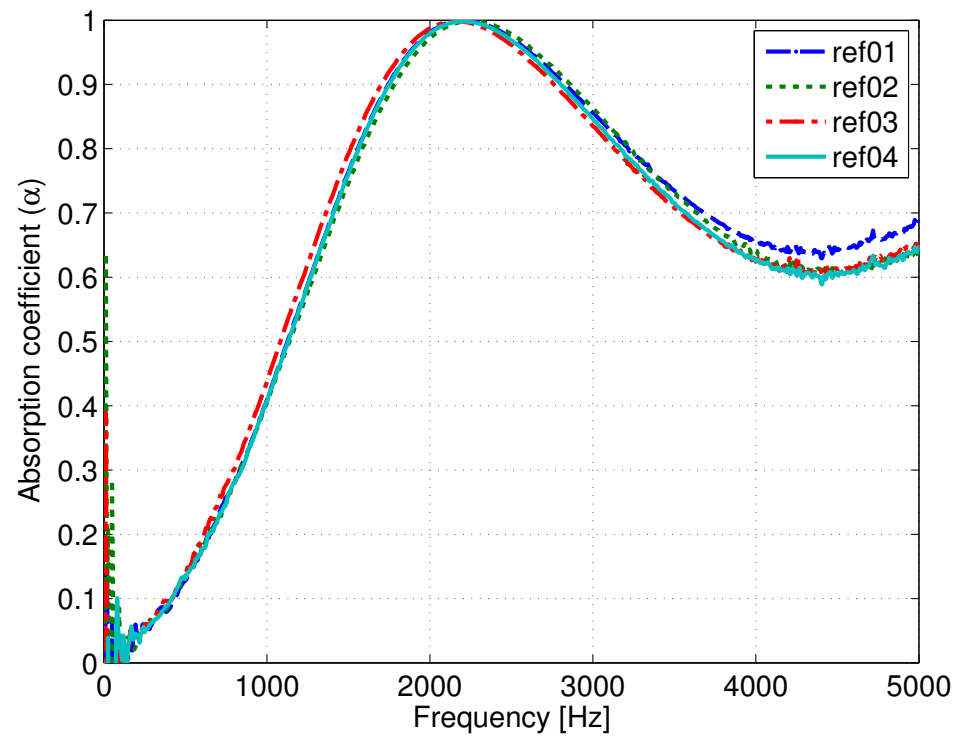

Figure 12: Repeatability of the elaboration process on absorption coefficient

\subsubsection{Physical interpretation of the frequency evolution of the ab- sorption coefficient}

The absorption coefficient is very low below $500 \mathrm{~Hz}$. At this frequency, the thickness of the sample is about $0.03 \lambda$ where $\lambda=c / f$ is the acoustic wavelength ( $c$ being the sound velocity and $f$ the frequency), hence the amount of acoustic energy inside the porous material is not sufficient to ensure dissipation through viscous and thermal effects. Then the absorption coefficient increases up to 2.2 
$\mathrm{kHz}$ where all the energy is dissipated in the material. This occurs in general at a frequency such that the wavelength is about four times the thickness of the material. More precisely, this maximum value is obtained when the imaginary part of the surface impedance $Z_{s}$ of the sample reaches a null value, and at the same time the real part of $Z_{s}$ is around $\rho_{0} c, \rho$ being the density of air. $Z_{s}$ is defined as the ratio between the acoustic pressure and the acoustic velocity both measured at the surface of the sample. The frequency evolution of $Z_{c}$ will be presented in figure 14. Between 2 and $4 \mathrm{kHz}$, the absorption coefficient decreases because the imaginary part of the surface impedance increases. Above $4 \mathrm{kHz}$, the absorption coefficient increases again since the wavelength becomes of the same order of magnitude as the thickness of the material, resulting in stronger interactions between acoustic waves and microstructure, inducing higher energy losses.

\subsubsection{Results}

The absorption coefficient of four types of samples (29 $\mathrm{mm}$ diameter) is presented in figure 13. All the curves exhibit a well identified maximum in the frequency range of interest. The maximum absorption occurs at a lower frequency for samples $30 \mathrm{~A}$ and $70 \mathrm{~A}$, around $1700 \mathrm{~Hz}$ : at this frequency the thickness of the sample corresponds almost to $\lambda / 10$ where $\lambda$ is the acoustic wavelength. The ref and $25 \mathrm{H}$ curves exhibit maxima between $2200 \mathrm{~Hz}$ and $2400 \mathrm{~Hz}$. As a consequence, the sample $30 \mathrm{~A}$ is the most efficient in the low frequency domain whereas the $25 \mathrm{H}$ is the less efficient in this domain.

\section{Modelling of the acoustic absorption perfor- mances of silicone foams}

The empiric Delany-Bazeley (DB) model [28] constitutes one of the most popular and simplest models for describing the acoustic behavior of porous materials, using a single parameter, namely the resistivity $\sigma$. It has been used in a first attempt to check if this very simple model can be used to describe the behavior of the silicone foams of interest with only one paramater. On the other side, the Johnson-Champoux-Allard (JCA) [29] model uses five intrinsic properties of the material, namely the flow resistivity $\sigma$, the porosity $\Phi$, the tortuosity $\alpha_{\infty}$, the viscous characteristic length $\Lambda$ (VCL), and the thermal characteristic length $\Lambda^{\prime}$ (TCL). The VCL describes the viscous effect when the fluid is in contact with the frame of the porous media. It has an order of magnitude near to the size of the smallest inhomogeneity of the material. The TCL is used to represent the thermal exchanges between the solid structure and the fluid. Its order of magnitude is typically equal to the largest pore radius of the foam. Compared to DB model, the JCA model describes more precisely the physics of the interaction between the acoustic waves and the pores of the material. However, it requires the knowledge of 5 parameters, which must be identified either by 


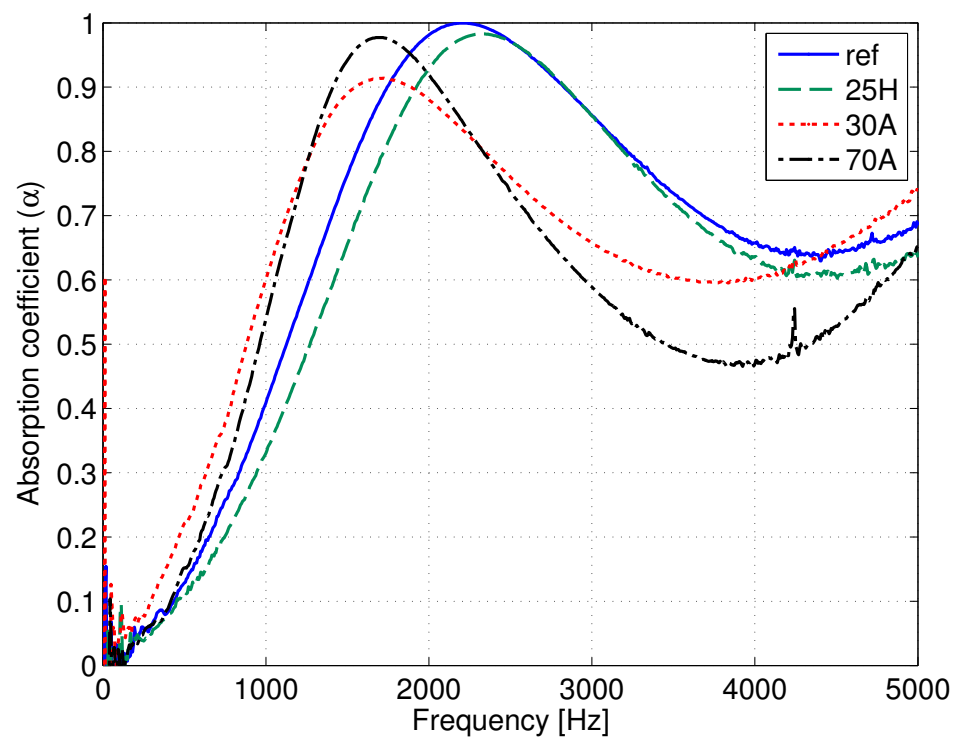

Figure 13: Influence of elaboration process on sound absorption coefficient

direct and indirect techniques which are available in literature: the open porosity, the flow resistivity and the thermal permeability can be determined with an acceptable accuracy using the standard direct techniques. However, the three others variables are difficult to identify with a good degree of confidence. In order to overcome this, it is generally possible to use an inverse method based on an optimization procedure [25], provided that the sensitivity of the parameters is large enough [31]. Finally, note that the use of Biot-Allard model, that accounts for elastic waves within the skeleton, is not necessary in our case since no skeleton resonances of the silicone media are observed (see Fig. 12).

\subsection{Model updating}

The model updating procedure uses a cost function $c f$ to minimize which is based on the measurement of the surface impedance of the material. This function writes

$$
\begin{array}{r}
c f=\Sigma\left(\left(\left|\operatorname{Re}\left(Z_{s}^{e}\right)-\operatorname{Re}\left(Z_{s}^{m}\right)\right|\right.\right. \\
\left.\left.+\mid \operatorname{Im}\left(Z_{s}^{e}\right)-\operatorname{Im}\left(Z_{s}^{m} \mid\right)\right)^{2}\right)
\end{array}
$$

where $Z_{s}^{e}$ is the estimated surface impedance, $Z_{s}^{m}$ is the meausured surface impedance, Re stands for real part and $I m$ for imaginary part.

The minimization process is based on the Nelder-Mead algorithm [32]. The bounds used in the analysis are $1<\alpha_{\infty}<4,70 \mu \mathrm{m}<\mathrm{VCL}<365 \mu \mathrm{m}$ and 
$70 \mu \mathrm{m}<\mathrm{TCL}<500 \mu \mathrm{m}$.

The values of the tortuosity, VCL and TCL identified after convergence of the procedure are $\alpha_{\infty}=2.52, \mathrm{VCL}=60 \mu \mathrm{m}$ and TCL $=420 \mu \mathrm{m}$.

The figure 14 shows the comparison between the experimental and the numerical surface impedance results.

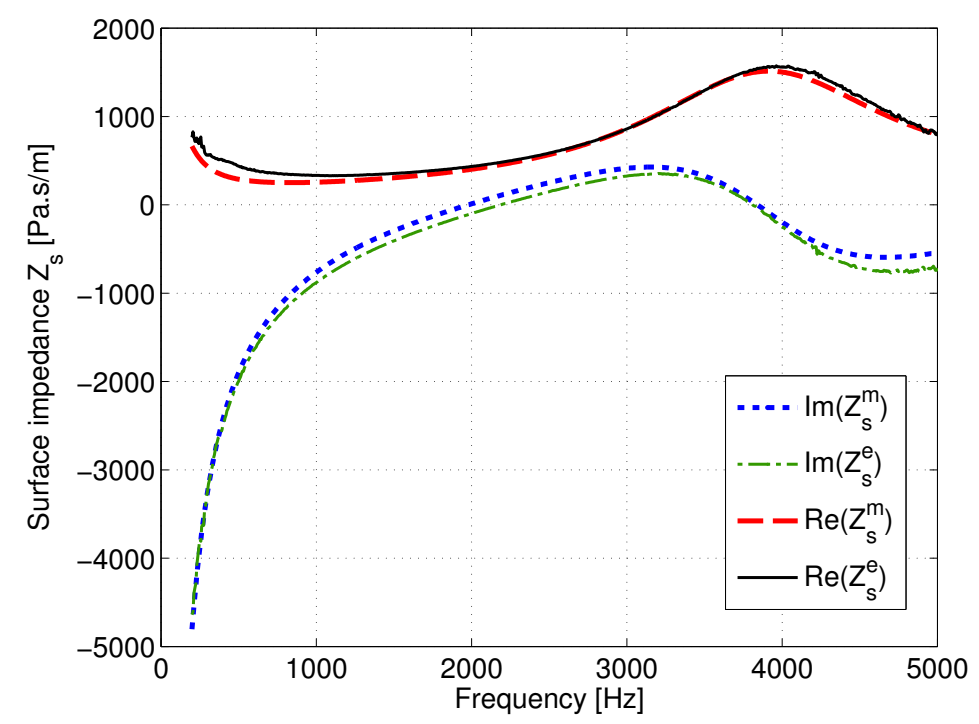

Figure 14: Experimental (e) and numerical (m) frequency evolution of surface impedance of sample ref

Fig.15 shows the same comparison on the absorption coefficient. It can be observed that the JCA model, coupled with the inverse method, provides an accurate description of the acoustical behaviour of the silicone foam, whereas the Delany-Bazley model does not fit. This indicates that the resistivity is not, by itself, sufficient to capture the physics of the acoustic phenomenon occurring in the silicone foam whereas tortuosity, viscous and thermal losses effects are properly captured by the JCA model. This confirms the motionless skeleton assumption of JCA model that will be used in the following.

The inverse procedure used above provides good results for estimating the acoustic performances of the material of interest. However, a direct estimation of the VCL and TCL could confirm the values obtained above. The technique proposed by F. Chevillotte et al.[33] is used here for estimating their values from the knowledge of the microstructure topology. Mean values of the pores and inter-pores sizes are used to obtain an experimental estimation of the VCL and the TCL, which are reported in the table 8.

As it can be seen, the two approaches provide consistent results. Hence, depending of the available setup, any of the two techniques may be used to identify these two parameters. 


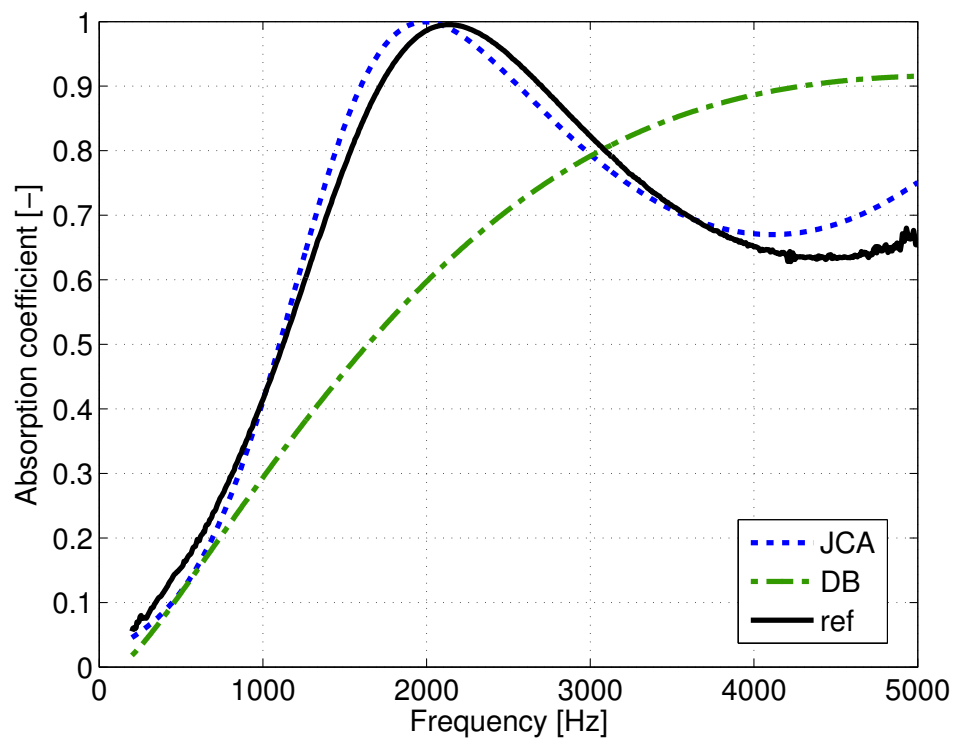

Figure 15: Experimental (continuous line) and numerical (dashed lines, JCA and DB models) frequency evolutions of the absorption coefficient results after using the inverse method optimisation on sample ref

\begin{tabular}{|c|c|c|c|}
\hline Parameter & $\begin{array}{c}\text { Experimental } \\
{[\mu \mathrm{m}]}\end{array}$ & $\begin{array}{c}\text { Numerical } \\
{[\mu \mathrm{m}]}\end{array}$ & $\begin{array}{c}\text { Relative } \\
\text { diff. }[\%]\end{array}$ \\
\hline VCL & 68 & 60 & 8.8 \\
\hline TCL & 385 & 420 & 9 \\
\hline
\end{tabular}

Table 8: VCL and TCL obtained from direct ("Experimental") and inverse ("Numerical") procedures on sample ref 


\subsection{Estimated parameters for different cases}

The inverse method is performed for the three other samples. The identified values are listed in table 9 .

\begin{tabular}{|c|c|c|c|c|}
\hline \multirow{2}{*}{ Sample } & Parameter & $\begin{array}{c}\text { Experi- } \\
\text { mental } \\
{[\mu \mathrm{m}]}\end{array}$ & $\begin{array}{c}\text { Nume- } \\
\text { rical } \\
{[\mu \mathrm{m}]}\end{array}$ & $\begin{array}{c}\text { relative } \\
\text { gap } \\
{[\%]}\end{array}$ \\
\hline \multirow{2}{*}{$70 \mathrm{~A}$} & VCL & 83 & 90 & 7.8 \\
\cline { 2 - 5 } & TCL & 423 & 470 & 11.1 \\
\hline \multirow{2}{*}{$30 \mathrm{~A}$} & VCL & 51 & 55 & 7.3 \\
\cline { 2 - 5 } & TCL & 369 & 484 & 8.7 \\
\hline \multirow{2}{*}{$25 \mathrm{H}$} & VCL & 97 & 98 & 1 \\
\cline { 2 - 5 } & TCL & 503 & 480 & 4.6 \\
\hline
\end{tabular}

Table 9: VCL and TCL obtained from direct ("Experimental") and inverse ("Numerical") procedures on samples $70 \mathrm{~A}, 30 \mathrm{~A}$ and $25 \mathrm{H}$

It can be observed from figure 16, that the values of the VCL and TCL (listed in table 9) obtained from the inverse method describe with a good degree of accuracy the acoustical behavior of the sample $25 \mathrm{H}$. Concerning sample $30 \mathrm{~A}$, it may be observed in Fig.17 that the JCA model is only able to properly capture the acoustic behavior of the material up to $2500 \mathrm{~Hz}$. Above that value, some physical effects may explain the difference observed in the absorption coefficient evolution. In particular, the sample 30A exhibits a particularly high value of flow resistivity (see table 7 ) the optimized values and the models could not correctly depict the behaviour of the sample foam 30A. The gap between experimental and modelled curves could come from the exceptional properties of the foam: high value of the resistivity $\sigma$ (listed in table 7 ) of the sample 30A, a high closed pore ratio (see table 5). Indeed, closed cells should not be affected by the acoustic wave. However, this could occur if the closed cells are trapped in a soft material such as silicone. The discrepancies observed in the upper frequency range suggest that both the JCA model and the provided porosity are not capturing exactly the physics of sample $30 \mathrm{~A}$ above $2.5 \mathrm{kHz}$. A deeper investigation on the effect of closed cell contents on the acoustic properties of silicone foams may be required to obtain a description of the material of interest up to $5 \mathrm{kHz}$.

The same observations can be made for the sample $70 \mathrm{~A}$, for which the comparison between experimental and optimized JCA model is shown in figure 18 . The acoustical behavior is well described in the range $[0-2500] \mathrm{Hz}$, while discrepancies are observed in the upper frequency range.

\section{Conclusions}

In this study, the link between elaboration process, pore size morphology, nonacoustical parameters and sound absorption performances of silicone foams have 


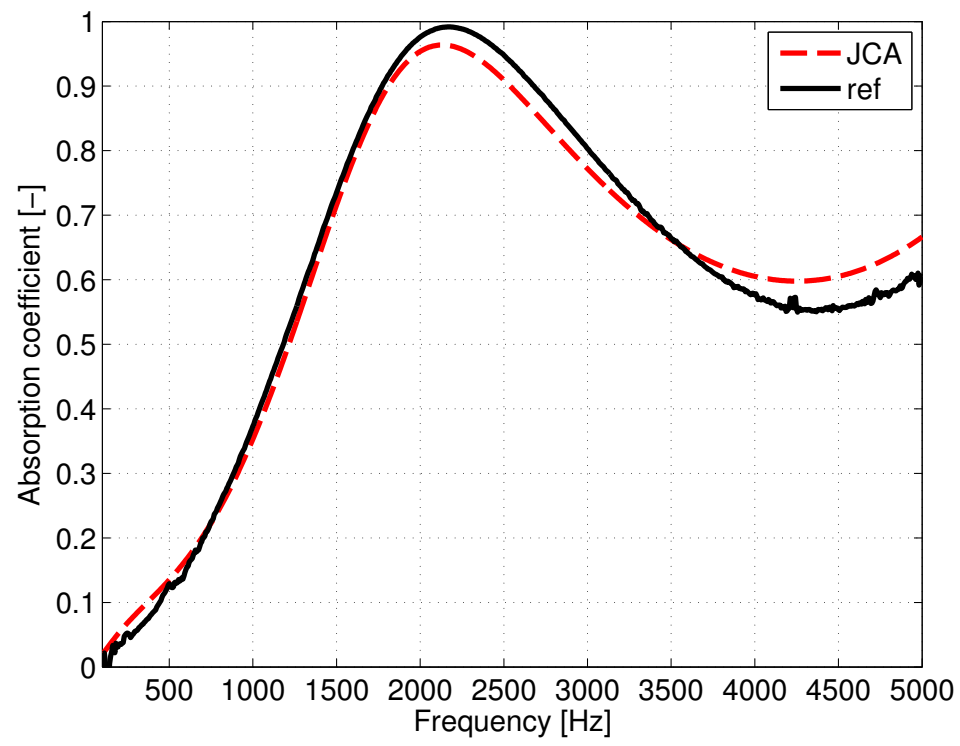

Figure 16: Comparison between the experimental (continuous line) and the numerical (dashed line) for the absorption coefficient on sample $25 \mathrm{H}$

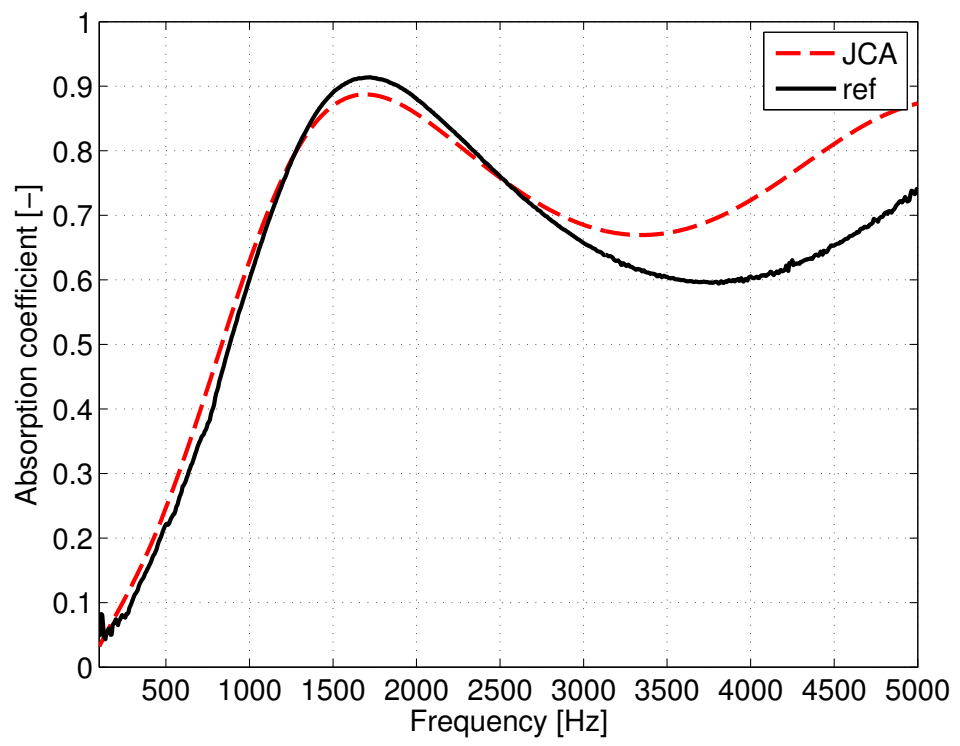

Figure 17: Experimental (continuous line) and numerical (dashed line, JCA model) frequency evolutions of absorption coefficient on sample 30A 


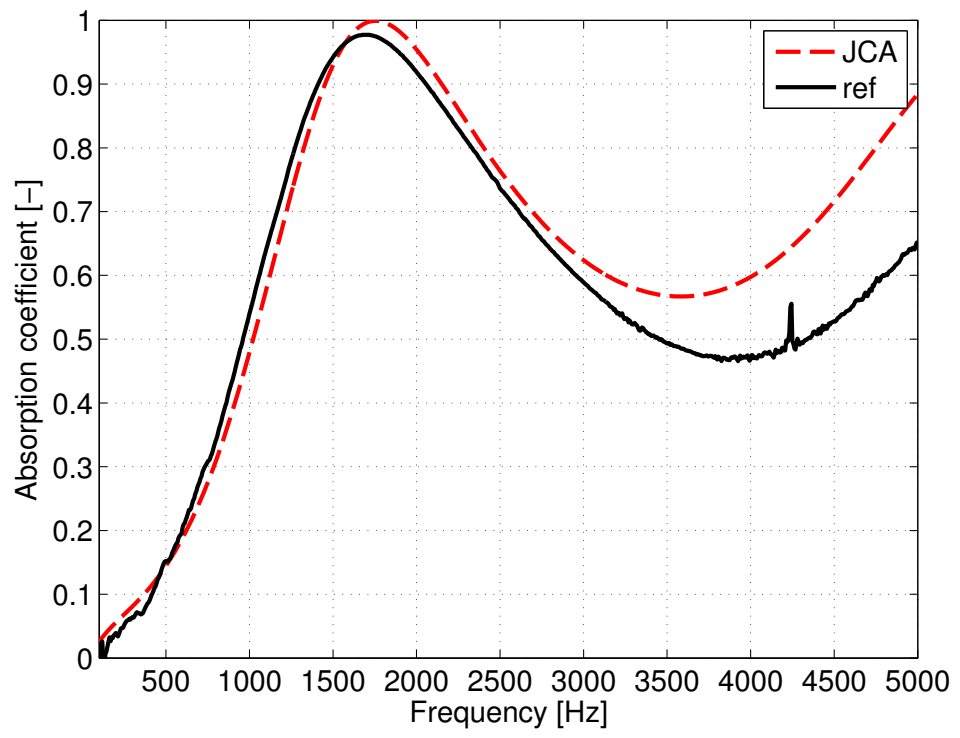

Figure 18: Experimental (continuous line) and numerical (dashed line, JCA model) frequency evolutions of absorption coefficient on sample $70 \mathrm{~A}$

been analysed. The elaboration parameters investigated are the components ratio, the use of a thinning agent in the composition, and the curing temperature. The link between pore size and elaboration process has been established. The mean cell size diameter can change between $0.76 \mathrm{~mm}$ to $1 \mathrm{~mm}$.

The sound absorption coefficient of the silicone foam can be improved in low frequencies by reducing the part of A component and be improved for high frequencies by adding oil.

The Johnson-Champoux-Allard is found to be a well suited model to describe the acoustical behaviour of the silicone foam with a good degree of confidence on a large frequency domain $(0$ to $2500 \mathrm{~Hz}$ ). For some particular samples, discrepancies may be observed on the $2500-5000 \mathrm{~Hz}$ band. However, the reference foam (corresponding to the recommendations in the technical datasheet of the material) is found to be well described by the Johnson-Champoux-Allard model up to $5 \mathrm{kHz}$. The inverse method presented in the paper is used to determine the tortuosity, the viscous and thermal characteristic lengths in a robust way. These parameters are found to be in good agreement with direct measurements performed on the samples of interest. The model may then be used in practical applications involving silicone foams with arbitrary thickness.

This work shows that silicone foams can be good candidates to design sound packages in recommended environments. 


\section{Acknowledgements}

This work was financed by the French National Research Agency under Grant No. ANR-12-JS09-008-COVIA. It has performed in cooperation wih the labex ACTION program (ANR-11-LABX-001-01).

\section{References}

[1] Nugent C, Blanes N, Fons J, Sáinz de la Maza M, Ramos M, Domingues F, et al. Noise in Europe 2014. European Environment Agency; 2014. 10/2014. ISSN 1977-8449.

[2] Pignier N. The impact of traffic noise on economy and environment: a short literature study: Performed within the scope of the ECO2 project Noise propagation from sustainable ground vehicles. KTH Royal Institute of Technology, Sweden; 2015. ISBN 978-91-7595-615-2.

[3] Simon F. Acoustic porous solutions for aircrafts: interior and exterior noises. In: Symposium on the Acoustics of Poro-Elastic Materials. Stockholm; 2014. p. 1-10.

[4] Cherng J. Smart Acoustic Material for Automotive Applications. Henry W. Patton Center for Engineering Education and Practice, The University of Michigan-Dearborn Henry; 2005.

[5] Allard JF, Atalla N. Propagation of sound in porous media: modelling sound absorbing materials. John Wiley \& Sons; 2009.

[6] Zhu P, Cao Z, Chen Y, Zhang X, Qian G, Chu Y, et al. Glycolysis recycling of rigid waste polyurethane foam from refrigerators. Environmental technology. 2014;35(21):2676-2684.

[7] Ignatyev IA, Thielemans W, Vander Beke B. Recycling of polymers: a review. ChemSusChem. 2014;7(6):1579-1593.

[8] Ridha M, Shim V. Microstructure and tensile mechanical properties of anisotropic rigid polyurethane foam. Experimental mechanics. $2008 ; 48(6): 763-776$.

[9] Deschanel S, Vanel L, Godin N, Maire E, Vigier G, Ciliberto S. Mechanical response and fracture dynamics of polymeric foams. Journal of Physics D: Applied Physics. 2009;42(21):214001.

[10] Luo H, Lu J, Ren S, Fang G, Jiang G. Studies of Polyvinyl Alcohol/Alkali Lignin/Silica Composite Foam Material (PLCFM). BioResources. 2015;10(3):5961-5973.

[11] Wang CN, Torng JH. Experimental study of the absorption characteristics of some porous fibrous materials. Applied Acoustics. 2001;62(4):447-459. 
[12] Atalla N, Amedin C, Atalla Y, Panneton R, Sgard F. Development of new high acoustical performance sound absorbing materials to decrease noise at low frequencies. Tech rep A-370. Montreal (Quebec): IRSST; 2004.

[13] Doutres O, Atalla N, Dong K. Effect of the microstructure closed pore content on the acoustic behavior of polyurethane foams. Journal of Applied Physics. 2011;110(6):064901-064901.

[14] Zhang C, Li J, Hu Z, Zhu F, Huang Y. Correlation between the acoustic and porous cell morphology of polyurethane foam: Effect of interconnected porosity. Materials \& Design. 2012;41:319-325.

[15] Basso MC, Pizzi A, Delmotte L. A New Approach to Environmentally Friendly Protein Plastics and Foams. BioResources. 2015;10(4):8014-8024.

[16] Jimenez M, Lesaffre N, Bellayer S, Dupretz R, Vandenbossche M, Duquesne $\mathrm{S}$, et al. Novel flame retardant flexible polyurethane foam: plasma induced graft-polymerization of phosphonates. RSC Advances. 2015;5(78):6385363865 .

[17] Tokiwa Y, Calabia BP, Ugwu CU, Aiba S. Biodegradability of plastics. International journal of molecular sciences. 2009;10(9):3722-3742.

[18] Coons J, McKay M, Hamada M. A Bayesian analysis of the compression set and stress-strain behavior in a thermally aged silicone foam. Polymer degradation and stability. 2006;91(8):1824-1836.

[19] Perrot C, Chevillotte F, Panneton R. Bottom-up approach for microstructure optimization of sound absorbing materials. The Journal of the Acoustical Society of America. 2008;124(2):940-948.

[20] Matousek T, Ponizil P, Kremen F, Buresova I, Dvorakova P. Pore Size Estimation. In: Proceedings of the 4th WSEAS International Conference on Energy and Development - Environment - Biomedicine. GEMESED'11. Stevens Point, Wisconsin, USA: World Scientific and Engineering Academy and Society (WSEAS); 2011. p. 372-377.

[21] Doutres O, Atalla N, Dong K. A semi-phenomenological model to predict the acoustic behavior of fully and partially reticulated polyurethane foams. Journal of Applied Physics. 2013;113(5).

[22] Doutres O, Ouisse M, Atalla N, Ichchou M. Impact of the irregular microgeometry of polyurethane foam on the macroscopic acoustic behavior predicted by a unit-cell model. The Journal of the Acoustical Society of America. 2014;136(4):1666-1681.

[23] Biot MA. Mechanics of deformation and acoustic propagation in porous media. Journal of applied physics. 1962;33(4):1482-1498. 
[24] Dauchez N, Etchessahar M, Sahraoui S. On measurement of mechanical properties of sound absorbing materials. In: 2nd Biot Conference on Poromechanics. Grenoble (France); 2002. p. 1-4.

[25] Atalla Y, Panneton R. Inverse acoustical characterization of open cell porous media using impedance tube measurements. Canadian Acoustics. 2005;33(1):11-24.

[26] Lee CL, Spells S. Sound Absorption Property of Platinum Catalyzed Silicone RTV Foam. Journal of Cellular Plastics. 1982;18(3):174-177.

[27] Kumar A, Mollah AA, Keshri AK, Kumar M, Singh K, Rallabhandi KDVS, et al. Development of Macroporous Silicone Rubber for Acoustic Applications. Industrial \& Engineering Chemistry Research. 2016;55(32):87518760 .

[28] Delany M, Bazley E. Acoustical properties of fibrous absorbent materials. Applied acoustics. 1970;3(2):105-116.

[29] Allard JF, Champoux Y. New empirical equations for sound propagation in rigid frame fibrous materials. The Journal of the Acoustical Society of America. 1992;91(6):3346-3353.

[30] Schneider C, Rasband W, Eliceiri K. NIH Image to ImageJ: 25 years of image analysis. Nature methods. 2012;9(7):671-675.

[31] Ouisse M, Ichchou M, Chedly S, Collet M. On the sensitivity analysis of porous material models. Journal of Sound and Vibration. 2012;.

[32] Singer S, Nelder J. Nelder-mead algorithm. Scholarpedia. 2009;4(7):2928.

[33] Chevillotte F, Perrot C, Guillon E. A direct link between microstructure and acoustical macro-behavior of real double porosity foams. The Journal of the Acoustical Society of America. 2013;134(6):4681-4690. 